two became positive on recalculation and the rest negative.

\section{Discussion}

All three methods performed well on a small but microbiologically defined panel of serum samples. The manufacturers of commercial serology kits must maintain a balance between sensitivity (true positives) and specificity (true negatives). The Amrad EIA kit had excellent sensitivity but had the lowest specificity of the three tests. The Orion EIA had the best specificity but the lowest sensitivity. The Orion dry latex test had the best compromise with very good sensitivity and specificity.

The Orion dry latex total antibody test was simple and quick to perform. Most serum samples gave clear cut results but one serum showed non-specific agglutination. When retested with more vigorous mixing this serum was read as negative. The major advantage of the dry latex test is the ability to test an individual serum. Each test card contains three test wells. The card may easily be cut in three to perform one test at a time. This has cost and convenience advantages over the EIA tests in that a full set of positive and negative controls as well as reference serum samples do not have to be run to test a single serum. However, automated EIA tests are more convenient for running large numbers of samples.

Based on the results of this study, the Orion Pyloriset dry latex total antibody test is recommended for laboratories which receive small numbers of requests for $H$ pylori antibody serology.

1 Goodwin CS, Blincow EW, Warren JR, Waters TE, Sanderson CR, Easton L. Evaluation of cultural techniques for isolation of Campylobacter pyloridis from endoscopic biopsies of gastric mucosa. $\mathcal{F}$ Clin Pathol 1985;38:1127-31.

2 Pinkard KJ, Harrison B, Capstick JA, Medley G, Lambert JR. Detection of Campylobacter pyloridis in gastric mucosa by phase contrast microscopy. $\mathcal{f}$ Clin Pathol 1986;39:112by pha

3 Marshall BJ, Warren JR, Francis GJ, Langton SR, Goodwin CS, Blincow ED. Rapid urease test in the management of CS, Blincow ED. Rapid urease test in the management of Campylobacter pyloridis-a

4 Marshall BJ, Surveyor IJ. Carbon-14 urea breath test for the diagnosis of Campylobacter pylori associated gastritis. $f$ Nucl Med 1988;29:11-16.

5 Newell DJ, Stacey AR. The serology of Campylobacter pylori infections. In: Rathbone BJ, Headley RV, eds. Campylobacter pylori and gastroduodenal disease. Oxford: Blackwell Scientific Publications, 1989:74-82.

6 Salama SM, Wefuan JN, Shiro-Koulla S, Mbakop A, TagniSartre M, Ndam ECN, et al. Value of whole-cell antigen extracts for serologic detection of Helicobacter pylori. $\mathcal{F}$ Clin Microbiol 1993;31:3331-2.

7 Lin SK, Lambert JR, Schembri MA, Nicholson N, Finlay $\mathrm{M}$, Wong $\mathrm{C}$, et al. A comparison of diagnostic tests to $\mathrm{M}$, Wong $\mathrm{C}$, et al. A comparison of diagnostic tests to
determine Helicobacter pylori infection. $\mathcal{F}$ Gastroenterol Hepatol 1992;7:203-9.

8 Kramer MS. The reproducibility and validity of diagnostic tests. In: Clinical epidemiology and biostatistics. Berlin: Springer-Verlag, 1988:205-13.

\title{
Corynebacterium aquaticum septicaemia in a neutropenic patient
}

\author{
C Moore, $\mathrm{R}$ Norton
}

Division of Clinical

Microbiology,

Institute of Medical

and Veterinary

Science,

Frome Road,

Adelaide,

South Australia 5000 ,

Australia

C Moore

R Norton

Correspondence to:

Dr R Norton.

Accepted for publication

1 June 1995

\begin{abstract}
Corynebacteria are a well recognised cause of sepsis in the immunocompromised patient. Corynebacterium aquaticum, however, is rarely seen in the clinical setting, being an environmental organism associated with fresh water. A septicaemic episode caused by this organism in a 74 year old neutropenic woman with an indwelling central venous catheter is reported. It is postulated that the source of the organism was untreated stored rainwater which she used for showering. ( $F$ Clin Pathol 1995;48:971-972)
\end{abstract}

Keywords: Corynebacterium aquaticum, central venous catheter, septicaemia.
In the immunocompromised patient, corynebacteria are often implicated as a cause of sepsis. In particular, Corynebacterium jeikeium (CJK) and Corynebacterium Group D2 are frequently associated with catheter related sepsis and urinary tract infections, respectively. ${ }^{12}$ Corynebacterium aquaticum is an environmental organism associated with fresh water. ${ }^{3}$ It has been reported in association with neonatal meningitis and urinary tract infection, septicaemia in an elderly patient with diabetes, and relapsing peritonitis with continuous ambulatory peritoneal dialysis. ${ }^{3-6}$ The literature, however, is sparse and virtually confined to patients with some form of immunosuppression. Here, we describe a septicaemic episode caused by this organism in a neutropenic 
woman with an indwelling central venous catheter.

\section{Case report}

A 74 year old woman was admitted with a one week history of rigors, lethargy and bruising. She had been diagnosed with polycythaemia rubra vera 17 years previously and had been treated initially with venesection alone. Two months prior to this admission, she was treated with busulfan and radioactive phosphorus $\left({ }^{32} \mathrm{P}\right)$ for which a triple lumen, tunnelled, central venous catheter was inserted into the right subclavian vein. Her haematological parameters at this time were as follows: haemoglobin, $140 \mathrm{~g} / 1$ (normal range $115-165 \mathrm{~g} / \mathrm{l}$ ); packed cell volume, $58.5 \%(37-47 \%)$; platelets, $752 \times 10^{9} / 1\left(150-400 \times 10^{9} / 1\right)$; and white cell count, $25 \cdot 1 \times 10^{9} / 1\left(4 \cdot 0-11 \cdot 0 \times 10^{9} / 1\right)$. Following treatment, the patient's white cell count fell to $0.9 \times 10^{9} / 1$ with $50 \%$ neutrophils $\left(0.45 \times 10^{9} / 1\right)$.

The patient lived on a rural property and did not have access to treated town water. Stored rainwater was used for washing and showering.

On admission, the patient was clinically anaemic and febrile with a temperature of $38^{\circ} \mathrm{C}$. There were scattered ecchymoses on her legs. No other relevant clinical abnormalities were noted. In particular, there were no cardiac murmurs and no evidence of local infection at the insertion site of the central venous catheter. Over the next 48 hours she remained febrile with her temperature reaching $39^{\circ} \mathrm{C}$.

The patient's haematological parameters on admission were as follows: haemoglobin, $83 \mathrm{~g} / 1(115-165 \mathrm{~g} / 1)$; platelets, $21 \times 10^{9} / 1(150$ $\left.400 \times 10^{9} / 1\right)$; white cell count, $0.94 \times 10^{9} / 1$ $\left(4.0-11.0 \times 10^{9} / 1\right)$; neutrophils, $0.62 \times 10^{9} / 1$ $\left(2 \cdot 0-7 \cdot 5 \times 10^{9} / 1\right)$. A clinical diagnosis of polycythaemia in transformation was made. No further chemotherapy was given.

Three sets of blood cultures were analysed using the BACTEC NR860 system (Becton Dickinson). All sets grew a Gram positive bacillus subsequently identified as Corynebacterium aquaticum, which was sensitive to penicillin. The central venous catheter was removed and the tip sent for culture. This was done using the semi-quantitative method of Maki et al. ${ }^{7}$ Significant numbers of $C$ aquaticum and coagulase negative staphylococci were grown.

Treatment with intravenous benzylpenicillin, $1.8 \mathrm{~g}$ every four hours for seven days, was commenced with a good clinical response. The patient was discharged from hospital and continued on oral amoxycillin $500 \mathrm{mg}$ every six hours for a further 10 days. She remained well on review two weeks after discharge.

\section{Discussion}

Corynebacterium aquaticum is a catalase positive, non-spore forming, Gram positive rod normally found in natural fresh water. It has also been isolated from distilled water. ${ }^{8}$ Colonies grown on Columbia horse blood agar develop a characteristic yellow pigment after 24 to 48 hours of incubation. $C$ aquaticum can be mistaken for Listeria monocytogenes before pigmentation appears. Both organisms give similar Gram stains, are catalase positive, motile, and produce acid from sugar fermentation. ${ }^{8}$ In this case the organism was identified using an API Coryne (BioMerieux, Marcy l'Etoile, France). Major distinguishing characteristics between the two organisms are colonial morphology, absence of haemolysis and production of acid from mannitol and xylose by $C$ aquaticum.

Likely sources of the organism would be the stored, untreated rainwater used for showering and other domestic purposes. The portal of entry could have been the indwelling central venous catheter. An attempt was made to isolate the organism from a single sample of water taken from the domestic supply. This was unsuccessful and may have been due to sampling the rainwater tank itself rather than the biofilm from the shower head.

Prior to discharge, all patients with indwelling central venous catheters from this unit are instructed on aspects of catheter care. In addition, weekly flushing of the catheter with heparinised saline is done by a community nurse.

A variety of organisms have been associated with community acquired, catheter related infections. These include coagulase negative staphylococci, viridans streptococci, Staphylococcus aureus, pseudomonads, and a wide range of Gram negative organisms. ${ }^{9}$

Correct identification of the organism in this case led to a greater awareness of the social circumstances of the patient, ultimately leading to a reassessment of the need for an indwelling intravenous catheter.

We would like to thank Dr T Hughes and Dr J Ho, Division of Haematology, Institute of Medical and Veterinary Science, Adelaide, for permission to report this case.

Kerry-Williams SM, Noble WC. Group JK coryneform bacteria. F Hosp Infect 1987;9:4-10.

2 Soriano $F$, Fernandez-Roblas $R$. Infections caused by antibiotic resistant Corynebacterium group D2. Eur 7 Clin Microbiol Infect Dis 1988;7:337-41.

3 Tendler C, Bottone EJ. Corynebacterium aquaticum urinary tract infection in a neonate and concepts regarding the role of the organism as a neonatal pathogen. $¥$ Clin Microbiol of the organism

4 Beckwith DG, Jahre JA, Haggerty S. Isolation of Corynebacterium aquaticum from spinal fluid of an infant with bacterium aquaticum from spinal fluid of

5 Morris AJ, Henderson D, Bremner A, Collins JF. Relapsing peritonitis in a patient undergoing continuous ambulatory peritoneal dialysis due to Corynebacterium aquaticum. Infect 1986;13:151-6.

6 Weiner M, Werthamer S. Corynebacterium aquaticum septicemia. Am $\mathcal{F}$ Clin Pathol 1975;64:378-81.

7 Maki DG, Weise CE, Sarafin HW. A semiquantitative culture method for identifying intravenous catheter related infection. $N$ Engl f Med 1977;296:1305-9.

$8 \mathrm{Krech}$ T, Hollis DG. Corynebacterium and related organisms. In: Balows A, ed. Manual of clinical microbiology. 5th edn Washington: American Society for Microbiology, 1991: 277-86.

9 Haslett TM, Isenberg HD, Hilton E, Tucci V, Kay BG, Vellozzi EM. Microbiology of indwelling central intravascular catheters. $\widetilde{f}$ Clin Microbiol 1988;26:696-701. 